\title{
eCOti
DiAno
}

Revista Mídia e Cotidiano

ISSN: 2178-602X

Artigo Seção Temática

Volume 14, Número 1, jan-abr de 2020

Submetido em: 04/11/2019

Aprovado em: 29/01/2020

\section{Youtubers mirins e os vídeos unboxing: uma reflexão sobre a criança conectada nas tramas da publicidade contemporânea}

\section{Young youtubers and unboxing videos: a reflection on contemporary advertising and the web-connected child}

\author{
Marcelo de ANDRADE \\ Gisela G. S. CASTRO ${ }^{2}$
}

\begin{abstract}
Resumo
O objetivo deste artigo é problematizar um tipo específico de produção midiática que tem despertado crescente atenção e angariado um conjunto significativo de novos adeptos nos últimos anos: os chamados vídeos unboxing, veiculados em canais do YouTube. Por meio da análise crítica, argumentamos que esses vídeos, protagonizados por youtubers mirins, constituem um ambiente de forte associação entre a publicidade e as lógicas do entretenimento, uma espécie de brecha utilizada para interpelar as crianças como consumidoras e produzir subjetividades. À revelia das regulamentações que normatizam a publicidade infantil no Brasil, diversão e promoção de produtos se tornam indissociáveis e interdependentes nessa inquietante nova maneira de brincar da criança conectada às redes sociais on-line, como apontam os resultados da investigação.
\end{abstract}

Palavras-chave: Comunicação e consumo. Publicidade infantil. Unboxing. YouTube. Youtuber mirim.

\begin{abstract}
The aim of this paper is to problematize a specific type of media production that has attracted growing attention and a significant number of new fans in recent years: the socalled unboxing videos, which are shown on YouTube channels. Through critical analysis we argue that unboxing videos, starred by young youtubers, constitute an environment of strong association between advertising and the logics of entertainment, a kind of gap used

\footnotetext{
${ }^{1}$ Mestre em Comunicação e Práticas de Consumo pelo PPGCOM ESPM/SP com bolsa PROSUP/CAPES. Pesquisador integrante do GRUSCCO - Grupo CNPq de Pesquisa em Subjetividade, Comunicação e Consumo. Professor universitário com experiência na área de Publicidade e Propaganda, Comunicação e Design, com ênfase em Comunicação Digital. E-mail: marcelo_dandrade@ yahoo.com.br. ORCID: 00000002-5300-9258.

${ }^{2}$ Psicóloga, mestre e doutora em Comunicação e Cultura (UFRJ) com pós-doutorado em Sociologia no Goldsmiths College (University of London). Docente do Programa de Pós-graduação em Comunicação e Práticas de Consumo (ESPM-SP), coordena o Grupo CNPq de Pesquisa em Subjetividade, Comunicação e Consumo (Gruscco) e o GT Comunicação, consumo e subjetividade no Comunicon. E-mail: gcastro@espm.br. ORCID: 0000-0003-0662-3770.
} 
by marketing specialists to approach children as consumers and to produce subjectivities. In spite of current regulations for children's advertising, as pointed out by the research results, the promotion of products and having fun become inseparable and interdependent in this unsettling new way of playing adopted by children connected to online social networks.

Keywords: Communication and consumption. Advertising for children. Unboxing. YouTube. Young youtubers.

\section{Introdução}

Nos últimos anos, tem crescido o acesso a plataformas digitais para um contingente crescente de brasileiros. Tomando por base a pesquisa TIC Domicílios ${ }^{3}$, realizada anualmente pelo Cetic.br ${ }^{4}$ (Centro Regional de Estudos para o Desenvolvimento da Sociedade da Informação), observa-se que a presença da internet nos lares brasileiros tem aumentado ano a ano. Em 2018, cerca de $67 \%$ das residências brasileiras possuíam acesso à internet. Em 2016 e 2017, o montante correspondia a 54\% e 61\% respectivamente (CGI.Br, 2019; 2018; 2017). Trata-se, sem dúvida, de um aumento significativo em termos de novas formas de comunicação, interação e sociabilidade para um grupo crescente de brasileiros conectados às redes sociais on-line.

Diante desse panorama, chama atenção o conjunto de pequenos internautas que também se apropriam desses ambientes digitais. Dados da pesquisa TIC Kids Online ${ }^{5}$ realizada também pelo Cetic.br - apontam que, em 2018, cerca de $86 \%$ das crianças e adolescentes com idade entre 9 e 17 anos acessavam a internet com frequência no Brasil. Se refinarmos os dados da pesquisa com a finalidade de contemplar a menor idade referenciada pelo estudo - crianças entre 9 e 10 anos - o número de usuários nessa faixa etária atingiu, em 2018, a marca de 77\%, percentual superior ao verificado tanto em 2017 (74\%) quanto em 2016 (68\%). De modo pragmático, podemos considerar que, na atual conjuntura, 7 em cada 10 crianças brasileiras possuem acesso à grande rede.

\footnotetext{
${ }^{3}$ Disponível em: <https://www.cetic.br/tics/domicilios/2018/domicilios/A4/>. Acesso em: 23 jan. 2020.

${ }^{4} \mathrm{O}$ Cetic.br tem por objetivo monitorar a adoção das tecnologias de informação e comunicação (TIC), em particular, o acesso e o uso de computador, internet e dispositivos móveis. Foi criado em 2005 e é um departamento do Núcleo de Informação e Coordenação do Ponto BR (Nic.br), uma entidade civil, sem fins lucrativos, que implementa decisões e projetos do Comitê Gestor da Internet no Brasil.

${ }^{5}$ Disponível em: <https://www.cetic.br/tics/kidsonline/2018/criancas/A1C/>. Acesso em: 23 jan. 2020.
} 


\section{míDiA

Seguindo uma curva ascendente que caminha na mesma direção, a disponibilidade de conteúdo voltado ao público infantil no ecossistema digital também vem aumentando e já representa uma parcela considerável das produções que estão disponíveis no YouTube, por exemplo. Em estudo realizado pelo ESPM Media Lab em 2015, Luciana Corrêa identificou que dos 100 canais com maior audiência na plataforma de vídeos, 36 deles eram direcionados ou continham conteúdo voltado ao público infantil (CORRÊA, 2015). Ao atualizar a pesquisa, em 2016, Corrêa constatou que o número de canais com apelo ao público infantil havia saltado para 48 em cada 100 (CORRÊA, 2016). Desse modo, entre os canais mais populares na divisão brasileira do site, praticamente a metade deles produzem ou compartilham, em alguma medida, conteúdos que são endereçados às crianças.

Embora o Google, empresa responsável pelo YouTube, apresente em suas políticas de uso a informação de que no Brasil a idade mínima para se ter uma conta na plataforma é de $18 \operatorname{anos}^{6}$, o que se verifica é uma significativa profusão de canais destinados ao público infantil.

Não por acaso, frente à crescente adesão de crianças à plataforma, bem como ao aumento progressivo na oferta de entretenimento para o público infantil, o YouTube se estabelece como um espaço oportuno para que diferentes empresas fabricantes de produtos infantis possam interpelar seus pequenos consumidores. No entanto, tal interpelação não se vale dos já consagrados breaks comerciais, mas ocorre por meio da inserção publicitária imbricada às próprias produções de entretenimento.

Este artigo é um desdobramento de pesquisa acadêmica que buscou compreender como o crescente número de crianças conectadas nas redes digitais propicia a produção de novas subjetividades, bem como o surgimento de novos modos de interpelar a criança enquanto consumidora. Para tanto, nos debruçamos sobre um formato que tem ganhado destaque nos últimos anos: os chamados vídeos unboxing. Termo em inglês cuja livre tradução seria "tirar da caixa", os vídeos unboxing apresentam produtos sendo desembalados de maneira informal e divertida, ao mesmo tempo em que são demonstrados com riqueza de detalhes. De acordo com o ESPM Media Lab, o número de

\footnotetext{
${ }^{6}$ Disponível em: <https://www.youtube.com/t/terms>. Acesso em: 23 jan. 2020.
} 


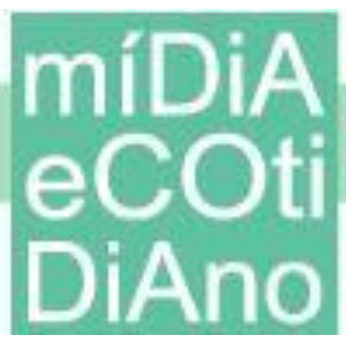

visualizações dos vídeos unboxing cresceu $975 \%$ de 2015 para 2016. Esse crescimento exponencial na audiência de vídeos nesse formato despertou a atenção também do mercado publicitário, uma vez que tem a capacidade de demonstrar tanto as características técnicas dos produtos, quanto as formas de uso e as experiências por eles proporcionadas.

Para refletir sobre como o mercado publicitário se apropria das produções culturais das crianças no YouTube, tomamos como objeto empírico o Canal da Lulu, protagonizado pela youtuber Luíza Sayuri. Por meio da plataforma SocialBlade ${ }^{7}$, identificamos os 200 canais mais populares no YouTube Brasil e definimos três critérios para o nosso recorte: 1) o canal deveria ser protagonizado por uma criança de até 12 anos de idade; 2) deveria pertencer à categoria entretenimento no YouTube; 3) ter mais de 1.500.000 de inscritos. Desse modo, dentre os 200 canais listados inicialmente, identificamos 10 que se enquadravam nos três critérios. Para chegar ao Canal da Lulu, elegemos a idade dos protagonistas dos canais como a regra de corte. Com apenas 5 anos de idade, Luíza foi a youtuber com a menor idade informada nos 10 canais que abarcavam os critérios definidos inicialmente. Trabalhamos com a metodologia de análise crítica, a qual busca descrever e interpretar o que se observa no campo empírico com base na fundamentação teórico-conceitual da pesquisa e, assim, trazer elementos que contribuam para a compressão do modo como a publicidade tem lançado mão desse formato para interpelar e cativar a criança conectada, driblando as restrições vigentes e, ao mesmo tempo, contribuindo para a produção de subjetividades ao promover certos modos de brincar e ser criança no contemporâneo.

\section{Notas sobre a publicidade destinada à criança no Brasil}

A busca do mercado publicitário por narrativas e recursos capazes de cativar a atenção da criança e dialogar com ela não é uma novidade. Em meados dos anos 1990, por exemplo, foram ao ar anúncios que seriam rechaçados pelas regras atuais. O clássico comercial elaborado para promover uma linha de tesouras infantis intitulado Eu tenho, você não tem ${ }^{8}$, bem como o igualmente famoso comercial que promovia o produto de

\footnotetext{
${ }^{7}$ Disponível em: <https://socialblade.com/>. Acesso em: 23 jan. 2020.

${ }^{8}$ Disponível em: <https://www.youtube.com/watch?v=zMFqTzH_dn0>. Acesso em: 23 jan. 2020.
} 
uma grande fabricante de chocolate, intitulado Compre Baton ${ }^{9}$, são bons exemplos do modo ostensivo como a publicidade já interpelou a criança consumidora em outros tempos.

Embora propagandas como estas não sejam mais permitidas, ainda assim é preciso reconhecer que caminhamos a passos lentos quando o assunto é a efetividade das regulamentações que vigoram no Brasil. De modo geral, as normas se voltam para formatos midiáticos tradicionais, como a TV aberta, que em função das limitações regulamentares diminuiu drasticamente sua oferta de conteúdo ao público infantil. Por outro lado, essas mesmas regulamentações não vigoram no universo digital. Ao defendermos que este é um debate de fundamental importância, apresentamos a seguir alguns elementos que corroboram nossa inquietação com o cenário contemporâneo.

Conforme Gisela Castro (2018, p. 75), “a publicidade ao mesmo tempo interpela e constitui o seu público consumidor por meio da criação de narrativas exemplares de cunho persuasivo em favor de marcas, produtos e serviços". Em tempos de dispersão da atenção em um ecossistema comunicacional em que proliferam múltiplas plataformas de mídia e pela prevalência das lógicas de mercado que transformam qualquer interação social em oportunidade de negócios, cruzar entretenimento e publicidade tem sido uma solução estratégica recorrente.

O Código de Defesa do Consumidor $(\mathrm{CDC})^{10}$ dispõe, em seu artigo 37, sobre a proibição de toda publicidade enganosa e abusiva. É considerada abusiva a publicidade que incite à violência, explore o medo e se aproveite da deficiência de julgamento e experiência da criança. No artigo 36 do mesmo CDC também está previsto que a prática publicitária deve ser veiculada de tal forma que o consumidor fácil e imediatamente a identifique como tal. No entanto, a clara identificação daquilo que é publicidade ou não se torna mais dificultosa à medida que a promoção de produtos, sobretudo na cultura digital, se vale de práticas comunicacionais que entrelaçam, de modo nada evidente, a publicidade com as lógicas de entretenimento, como no caso do objeto empírico deste artigo: os vídeos unboxing publicados no Canal da Lulu. Em muitas dessas produções, o

\footnotetext{
${ }^{9}$ Disponível em: <https://www.youtube.com/watch?v=sBWu7ibZDVg>. Acesso em: 23 jan. 2020.

${ }^{10}$ Disponível em: <http://www.planalto.gov.br/ccivil_03/Leis/L8078.htm>. Acesso em: 23 jan. 2020.
} 


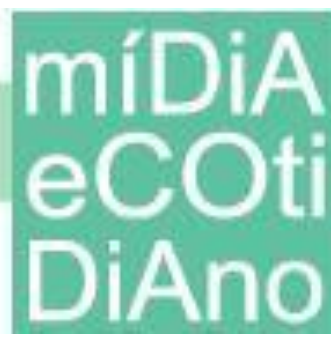

fator comercial está, frequentemente, embutido ao próprio conteúdo de entretenimento e quase nunca se revelando de modo evidente e claro ao consumidor. Trata-se de um formato em que o brincar e o demonstrar se mesclam de tal modo que a percepção do apelo comercial embutido nessas produções se naturaliza como parte de uma brincadeira que se tornou extremamente popular - e lucrativa para alguns.

Neste momento, no entanto, faz-se necessário contextualizar como se deu a seleção do vídeo analisado abaixo. Na plataforma do YouTube, selecionamos no Canal da Lulu todos os vídeos publicados no intervalo de julho de 2017 a julho de 2018 e listamos de acordo com o número de visualizações, do mais visualizado para o menos visualizado. Nesse conjunto de produções, observamos os vídeos que apresentavam, de alguma forma, o desembalar de brinquedos - unboxing. Dos três vídeos mais visualizados, selecionamos a produção abaixo por ser a única que apresentava alguma informação de que se trata de um conteúdo patrocinado.

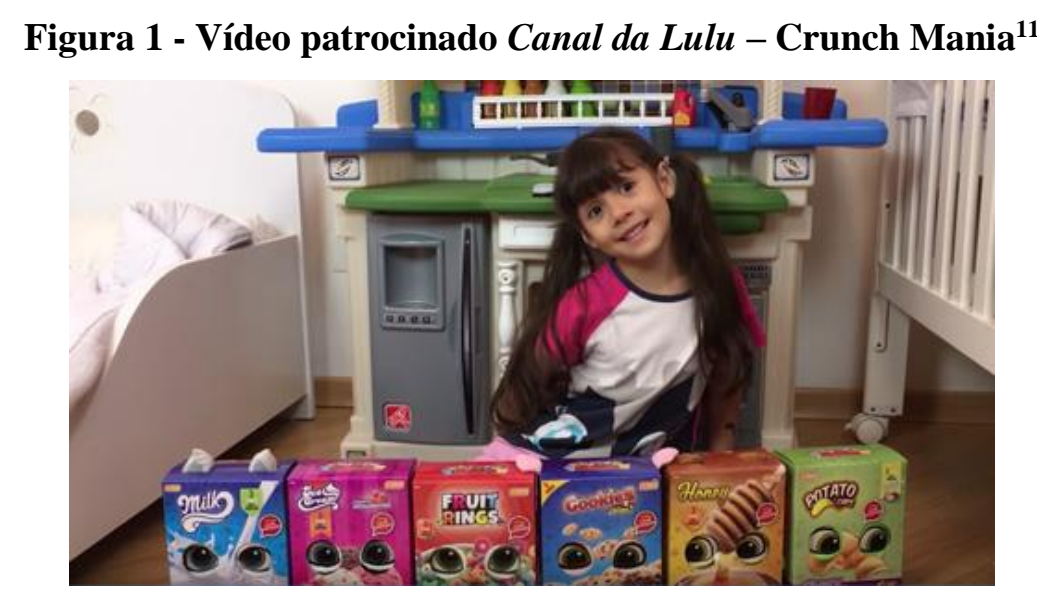

Fonte: Elaborado pelos autores.

Mesmo considerando que o vídeo analisado procura demonstrar a seus seguidores que há algum tipo de investimento comercial, ainda é carente e, ao nosso ver, insuficiente o modo com que essa informação é apresentada ao internauta. Ao examinarmos o vídeo Crunch Mania (Fig. 1), observamos que há na sua descrição a informação de que se trata de um vídeo patrocinado, confirmando a tese de que há aportes empresariais que rentabilizam a produção do canal. No entanto, vale destacar que, mesmo

\footnotetext{
${ }^{11}$ Disponível em: <https://www.youtube.com/watch?v=HQPcqHxG88E>. Acesso em: 23 jan. 2020.
} 


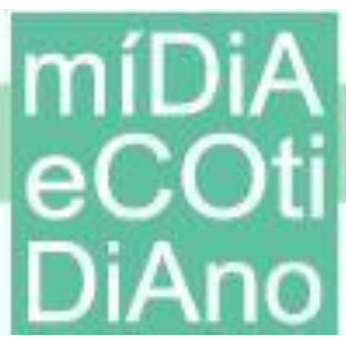

possuindo a informação da existência de patrocínio, ainda é insuficiente para informar o público, visto que esse dado só aparece na descrição do vídeo no canal e não no próprio conteúdo audiovisual.

A presença da informação apenas na descrição do vídeo pode ser apontada como parte da estratégia utilizada pelo canal. No momento em que estávamos selecionando nosso corpus empírico, o Canal da Lulu nos chamou a atenção por ser, até então, um dos poucos que apresentavam a informação de conteúdo patrocinado. Mas, na ocasião, tal informação era inserida no próprio vídeo, apresentada na abertura da produção audiovisual. Havia nos primeiros segundos do vídeo uma pequena faixa no canto inferior esquerdo com a seguinte frase: "Esse vídeo pode conter conteúdo promocional". Atualmente, pelo contrário, tal informação deixou de ser parte integrante do vídeo e foi realocada para a sua descrição. Assim, como argumenta Rogério Covaleski (2010), a mensagem publicitária paradoxalmente ganha sobrevida à medida que menos se parece com ela, e quanto menos se valha dos elementos tradicionais que constituem as narrativas publicitárias convencionais.

Não por acaso, ao longo dos quase 6 minutos do vídeo em questão, a youtuber apresenta o produto e suas características ao mesmo tempo em que, aparentemente, brinca e se diverte com ele. Se de um lado podemos considerar que a informação de conteúdo patrocinado é apresentada, por outro, vale questionar a posição secundária que tal informação ocupa, sendo rapidamente naturalizada como parte da performance executada pela pequena youtuber.

Mesmo reconhecendo que o vídeo abarca um viés mercadológico no intuito de promover determinados produtos, a narrativa da youtuber segue por um outro caminho. Luíza alega que ela mesmo teria selecionado e comprado os brinquedos que aparecem em seu canal. Nesse caso, tanto a posição da informação de conteúdo patrocinado - apenas na descrição do vídeo -, quanto a narrativa sustentada pela youtuber - que ela teria comprado o brinquedo demonstrado -, são elementos que contribuem para turvar ainda mais a fronteira que delimita a publicidade e o entretenimento. Nos comentários, disponível na página do vídeo, é frequente a curiosidade dos internautas em saber o local que Luíza teria adquirido o brinquedo demonstrado. Frases como "eu vou comprar no meu aniversário"; "onde você comprou? me responde" são reiteradamente presentes nos 


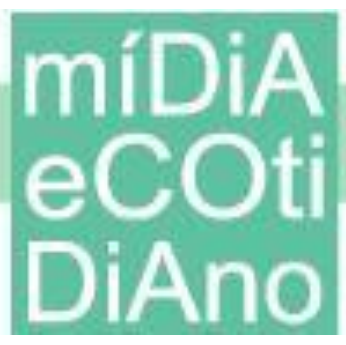

comentários. Como não poderia deixar de ser, a youtuber responde dizendo que o produto pode ser encontrado em qualquer loja de brinquedos ${ }^{12}$.

Em março de 2014, foi publicada a resolução 163 do Conselho Nacional dos Direitos da Criança e do Adolescente (CONANDA) ${ }^{13}$, órgão vinculado à Secretaria de Direitos Humanos da Presidência da República, que dispõe sobre a abusividade do direcionamento de publicidade e comunicação mercadológica à criança e ao adolescente. Segundo esta resolução que, de certo modo, reforça as normativas já presentes no $\mathrm{CDC}^{14}$, é considerado abusivo o direcionamento da comunicação mercadológica com a intenção de persuadir a criança para o consumo de serviços ou produtos, utilizando para isso qualquer dos nove elementos elencados pela resolução, sendo eles: 1) linguagem infantil, efeitos especiais e excesso de cores; 2) trilhas sonoras de músicas infantis ou cantadas por vozes de crianças; 3 ) representação de criança; 4) pessoas ou celebridades com apelo ao público infantil; 5) personagens ou apresentadores infantis; 6) desenho animado ou de animação; 7) bonecos ou similares; 8) promoção com distribuição de prêmios ou de brindes colecionáveis ou com apelo ao público infantil; 9) promoção com competições ou jogos com apelo ao público infantil.

A princípio, a validade dessa normativa se estenderia para todos os ambientes, incluindo eventos, espaços públicos, páginas de internet, spots de rádio, canais televisivos e assim por diante, independentemente do horário de veiculação. Cabe ponderar, como o faz Ekaterine Karageorgiadis (2017), que as normas que regulamentam a publicidade dirigida à criança no Brasil não pretendem bani-la, mas conter seus abusos. Uma vez que uma empresa exerce seu direito de fazer publicidade, seria obrigada, em contrapartida, a respeitar os princípios que regem tal prática na atual conjuntura brasileira.

A discussão sobre a publicidade dirigida à criança e seus desdobramentos acontece de maneira polarizada e, até mesmo, maniqueísta no Brasil. De um lado, estariam os defensores da garantia dos direitos das crianças diante dos efeitos

\footnotetext{
${ }^{12}$ Em janeiro de 2020, o YouTube conclui o processo de desabilitar os comentários referentes ao conteúdo infantil da plataforma. A iniciativa faz parte de uma série de medidas relativas à segurança dos usuários infantis.

${ }^{13}$ Disponível em: <http://www.direitosdacrianca.gov.br/conanda/resolucoes/163-resolucao-163-de-13-demarco-de-2014/view>. Acesso em: 23 jan. 2020.

${ }^{14}$ CDC - Código de Defesa do Consumidor.
} 


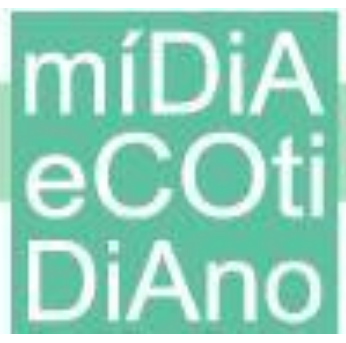

considerados danosos da publicidade. Tal visão confere à atividade mercadológica a razão principal para os males que acometem as infâncias contemporâneas. Do outro lado, estariam aqueles que defendem a não regulamentação por parte do Estado, argumentando que tal regulação acarretaria uma espécie de censura à liberdade de expressão (CRAVEIRO; BRAGAGLIA, 2017).

Em meio às disputas que configuram esse debate, não podemos ser ingênuos e conceder apenas à publicidade a causa única para os problemas que estariam surgindo no cotidiano infantil. Em sua pesquisa sobre a relação das crianças com a mídia e o consumo de produções jornalísticas na TV, Orofino (2015) pondera que, enquanto nos preocupamos apenas com a publicidade como se esta fosse a principal causadora dos males da vida contemporânea, deixaríamos de atentar para o conjunto de programas de TV e outras produções midiáticas que, em grande medida, seriam inapropriados para o público infantil. Conforme argumenta, o problema é maior e mais complexo que a proibição única e exclusiva da publicidade destinada às crianças, uma vez que tal proibição não irá livrá-las de apelos comerciais sedutores aos quais estão expostas em diferentes esferas da vida. Na realidade, segundo a estudiosa, tal proibição poderia gerar o efeito inverso de eventualmente prejudicar as crianças, pois a falta de publicidade afeta diretamente as cotas de patrocínio e apoio cultural à programação infantil, o que resultaria no encolhimento progressivo da oferta de conteúdo voltado para as crianças nos canais midiáticos com os quais convive grande parte desse público.

As tensões e disputas acerca do apelo publicitário na programação infantil demandam cautelosa reflexão. O estabelecimento de diretrizes que funcionem de maneira efetiva como guias para a prática publicitária nos parece um pressuposto razoável, notadamente quando se trata de normatizar a comunicação publicitária dirigida às crianças. Tornar a propaganda evidente aos olhos do público infantil deveria ser uma premissa consensual e amplamente adotada. No caso de certas produções como os vídeos unboxing, tal premissa teria a função de informar sobre o que está em andamento na aparente espontaneidade de uma brincadeira que se mostra tão atraente em nossos dias. No entanto, como procuramos demonstrar, as ações publicitárias inseridas em meio às produções de entretenimento tendem a embaçar as fronteiras entre o apelo comercial e a simples e inocente diversão. Tal mescla inquietante pode ser observada de modo 


\section{míDiA

recorrente nas publicações de grande parte das youtubers mirins que congregam legiões de jovens fãs em seus canais on-line.

\section{Youtubers mirins, vídeos unboxing e o apelo publicitário dirigido à criança conectada}

Antes de iniciarmos este tópico, vale salientar que, neste artigo, trataremos do termo youtubers sempre no feminino, uma vez que grande parte dessas pequenas personalidades que fazem sucesso na rede são meninas. Assim, não corremos o risco de causar confusão em relação ao tratamento do termo ao longo do texto.

De acordo com Renata Tomaz (2017), as primeiras notícias apresentadas pela grande imprensa brasileira acerca das youtubers mirins surgiram no ano de 2015, muito por causa do aumento progressivo de crianças que reuniam milhares de inscritos em seus canais no YouTube. Ao discorrer sobre o deslocamento das crianças para uma posição de destaque na cena midiática atual, a autora indica que a presença das youtubers mirins pode ser considerada, ao menos, sob dois pontos de vista.

Uma diz respeito ao reconhecimento da voz das crianças, vinculado a uma configuração de elementos históricos e socioculturais, que possibilitam conceber a participação das crianças na vida social. A outra condição está relacionada a um espaço disponível para que elas possam manifestar essa presença, em particular a mídia (TOMAZ, 2017, p. 36).

Acompanhando tal perspectiva, podemos considerar que os sites de rede social (boyd; ELLISON, 2007) se revelam como espaços disponíveis para que o público infantil possa manifestar sua presença e ganhar visibilidade. Nesse contexto, o YouTube configura um ambiente no qual a criança, de certo modo, ganha voz e traz para o âmbito público suas experiências, brincadeiras, bem como uma variedade de temas condizentes ao seu cotidiano.

É curioso notar que em grande parte das produções nas quais as youtubers mirins demonstram suas brincadeiras e situações cotidianas, há de modo recorrente a presença de bens de consumo. São objetos que não apenas contextualizam as produções exibidas, mas contribuem para demarcar hierarquias sociais e demonstrar estilos de vida que são invariavelmente atrelados ao consumo de tais bens. No entanto, antes de continuarmos 


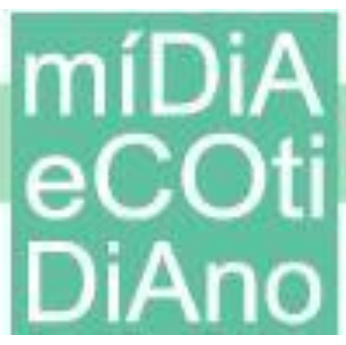

nesta linha de argumentação, faz-se necessário fundamentar o que entendemos por estilo de vida em meio à cultura do consumo, uma vez que se trata de uma expressão que pode ser compreendida de modos distintos.

Para Mike Featherstone (1995) a expressão estilo de vida pensada no âmbito da cultura do consumo implica uma consciência de si estilizada, uma compreensão que denota individualidade. Como ensina o estudioso, o cuidado com o corpo, as roupas, o discurso utilizado, os programas de entretenimento, as preferências de comida e bebida, a casa, o carro, bem como as opções de férias de uma pessoa são vistos como indicadores da individualidade do gosto e o senso de estilo de vida do indivíduo em questão.

De modo bastante elucidativo, João Freire Filho (2003, p. 73) explica que o estilo de vida "reflete a sensibilidade (ou a 'atitude') revelada pelo indivíduo na escolha de certas mercadorias e certos padrões de consumo e na articulação desses recursos culturais como modo de expressão pessoal e distinção social". A constituição do estilo de vida é uma prática fundamentalmente cultural e fortemente influenciada pelos signos que são apresentados, majoritariamente, pelos ambientes midiáticos e, em seguida, combinados em performances associadas a grupos específicos.

Por esse ponto de vista, em tese, qualquer pessoa poderia intercambiar de um estilo para outro, uma vez que no estilo de vida não há posições sociais nem eus individuais naturalmente organizados. Pelo contrário, conforme enfatiza Don Slater (2002), os indivíduos são compelidos a escolher, construir, manter, interpretar, negociar, exibir quem eles devem ser ou parecer, e para isso, usam uma variedade importante de recursos materiais e simbólicos.

Assim, para se ter um determinado estilo de vida, para partilhar de modos específicos de ser e viver, faz-se necessário, a princípio, aderir a certos bens de consumo que darão suporte para gozar de uma vida pautada pelo estilo escolhido. Até mesmo discursos que defendem uma visão crítica em relação aos excessos do consumismo, apontam recorrentemente para estilos de vida nos quais o consumo de certos tipos de bens seria mais indicado do que outros. O que não deixa de ser um paradoxo, tendo em vista que tal discurso anticonsumista pode acabar se tornando um nicho mercadológico altamente rentável, conforme pondera Isleide Fontenelle (2017), ao discorrer sobre o chamado consumo responsável. 
Estudiosos do consumo argumentam que "muito além do comportamento de compra, as práticas de consumo se articulam com a visibilidade midiática em um multifacetado processo sociocultural em que (...) mídia e consumo se combinam para fomentar modos de ser e estilos de vida" (CASTRO, 2018, p. 75). Ao salientar determinados bens de consumo que carregam seus valores e sentidos culturalmente constituídos, as youtubers mirins se valem da carga simbólica atribuída aos objetos para compor seu próprio estilo, ensejando uma atitude performática na qual a vida privada estaria se tornando progressivamente pública.

Ancorado nas reflexões apresentadas pelos trabalhos de Erving Goffman, Roger Silverstone (2002, p. 132) explica que

(...) a vida social é vista como uma questão de administração da impressão. Nosso mundo é um mundo de aparência visível. Vivemos numa cultura apresentacional em que a aparência é a realidade. Indivíduos e grupos apresentam suas faces ao mundo em cenários onde administram sua performance com mais ou menos confiança: palcos em que o que fazemos é para mostrar, para impressionar os outros e definir e manter nosso senso de nós mesmos, um senso de identidade, fora da visão de nossa audiência, podemos preparar a maquiagem, a transformação.

É nesse contexto de forte presença de objetos, bem como atitudes performáticas, que o unboxing ganha destaque entre as produções das youtubers mirins. Constitui-se, ao mesmo tempo, um formato capaz de demonstrar bens de consumo, mas também sustentar estilos de vida e hierarquias sociais. O caso das bonecas L.O.L Surprise ${ }^{15}$ é bastante elucidativo para essa questão. Lançada em 2016, a pequena boneca colecionável que praticamente cabe na palma da mão se tornou uma "febre" entre crianças espalhadas ao redor do mundo. Nos Estados Unidos, por exemplo, foi o brinquedo mais vendido em 2017, comercializando cerca de 2,5 milhões de unidades pelo mundo em apenas cinco meses (FELDMAN, 2017).

Além de ter utilizado as redes sociais, inclusive o unboxing, como vetores principais de divulgação, o que impressiona no caso desta boneca são os valores dos itens

15 Para mais detalhes sobre o produto, acessar página virtual do brinquedo. Disponível em: $<$ http://www.candide.com.br/lol/>. Acesso em: 23 jan. 2020. 


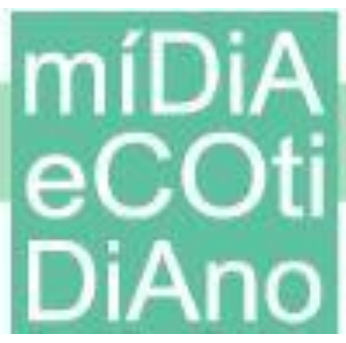

que fazem parte da trama de acessórios. Para se ter uma ideia, os valores variam de $\mathrm{R} \$$ 80,00 para as bonecas menos custosas e se aproximam ao patamar de quase $\mathrm{R} \$ 3.000,00$ para a casa da boneca que abrigaria a coleção. No vídeo intitulado Minha coleção de L.O.L Surpresa raras (Fig. 2), a protagonista do Canal da Lulu exibe o que diz ser a sua coleção de bonecas L.O.L "raras e ultra raras". Assim, a simples posse do produto seria, por si só, o suficiente para revelar as categorias sociais e demarcar suas hierarquias.

Figura 2 - Coleção L.O.L Surprise da youtuber Luiza Sayuri ${ }^{16}$

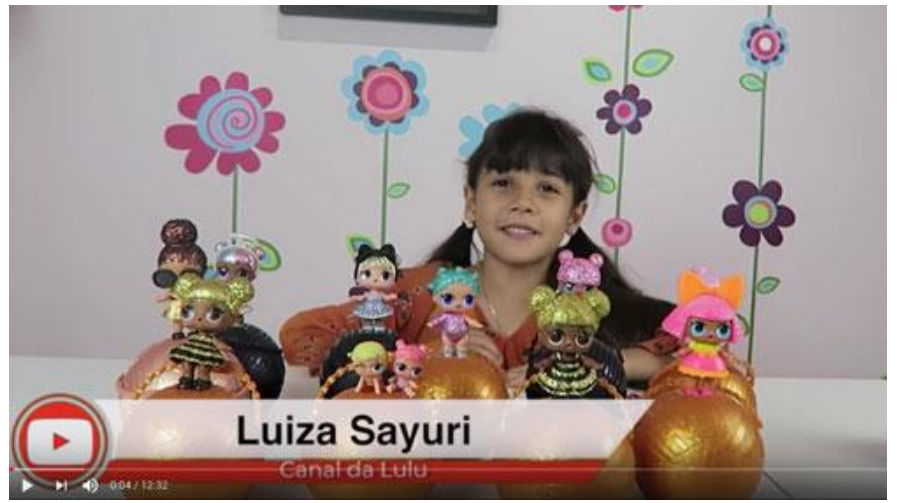

Fonte: Elaborado pelos autores.

Ao enfatizarem determinadas brincadeiras que necessitam de certas mercadorias para serem executadas, as youtubers mirins contribuem também para eleger certos modos de brincar como sendo os mais apreciados, divertidos e desejáveis. Tendo em vista que as youtubers se transformaram em "agentes de formação de opinião sobre uma dimensão de ser e estar no mundo" (PERES; TRINDADE, 2017, p. 2), essas figuras estariam se valendo desse posto de autoridade para revelar os modos considerados adequados e bemsucedidos de ser criança em uma contemporaneidade crescentemente conectada às redes sociais on-line.

Esse posto de referência conferido às youtubers mirins por parte de seus seguidores é observado com atenção e interesse também pelo mercado de produtos infantis. Devido à ampla visibilidade e capacidade de disseminação de conteúdo que as youtubers mirins detêm, diversas empresas de produtos infantis vislumbram em tais personagens uma oportunidade valiosa para tornar públicas as mercadorias que

\footnotetext{
${ }^{16}$ Disponível em: <https://www.youtube.com/watch?v=v5-somvmfUI>. Acesso em: 23 jan. 2020.
} 


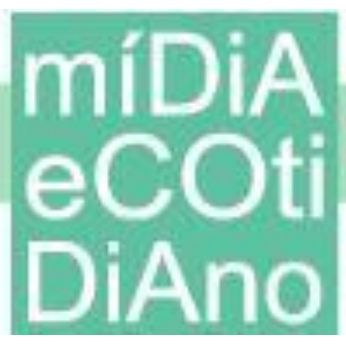

produzem, sobretudo, considerando que a geração consumidora da mídia digital tem essas “personalidades da internet” (LEÃO; PRESSLER, 2017) como os seus principais ídolos. $\mathrm{Na}$ esteira dessa visibilidade, diferentes empresas buscam vincular suas marcas e produtos ao cotidiano das youtubers mirins no intuito de atrair a atenção e o interesse de seus seguidores.

Para além de demonstrarem produtos e modos de uso, consideramos que as youtubers também contribuem para o processo de subjetivação daquilo que denominamos como a criança conectada. Trata-se de um modo de ser criança que tem nas redes sociais on-line um de seus principais vetores. Como ensina Castro (2018, p. 85), o coaching midiático das subjetividades diz respeito à "promoção de modos de ser e estilos de vida baseados em práticas de consumo na pedagogia social para o consumo desenvolvida pelos mais diversos dispositivos midiáticos". Tal "associação entre mídia e consumo resulta no coaching midiático dos estilos de vida e modos de ser" considerados exemplares em uma cultura fortemente marcada pela comunicação midiática e embebida em signos do consumo.

Sendo assim, consideramos os mais populares youtubers como agentes na promoção de modos de ser e estilos de vida pautados pelas lógicas do consumo. Atuam na consolidação de um modo de ser criança no qual estar sempre conectado à internet, bem como consumir certo tipo de bens se tornam imperativos preponderantes e indispensáveis para se gozar de uma boa vida. Uma vida tal qual a performada por certas youtubers mirins, com seus brinquedos e sua invejável popularidade.

Em meio às produções dessas pequenas personalidades infantis, há sempre uma ocasião em que convocam seus espectadores a permanecerem conectados aos seus canais. Tomaz (2017, p. 56) evidencia que há uma convocação reiterada por parte das youtubers para "assistirem seus vídeos, dizerem se gostaram ('dá um like'), deixarem seus comentários e serem parte dessa rede de amigos". Trata-se de um tipo de convocação que não acontece apenas para tornar tais figuras e suas brincadeiras ainda mais conhecidas, mas também para aumentar o "valor" mercadológico dos próprios canais no concorrido mercado das youtubers.

É sabido que algumas personalidades mirins monetizam seus canais enquanto brincam em frente à câmera para multidões de seguidores on-line. Tal fato pode ser 


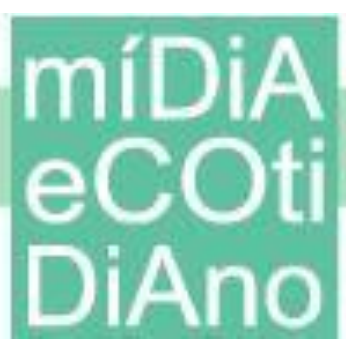

observado de modo contundente no caso do youtuber mirim Ryan, protagonista do canal Ryan's World $^{17}$. Trata-se de um garoto de apenas 8 anos de idade que possui mais de 22 milhões de seguidores e cujos vídeos já foram visualizados mais de 33 bilhões de vezes.

Figura 3 - O youtuber mais bem pago de 2018 e $2019^{18}$

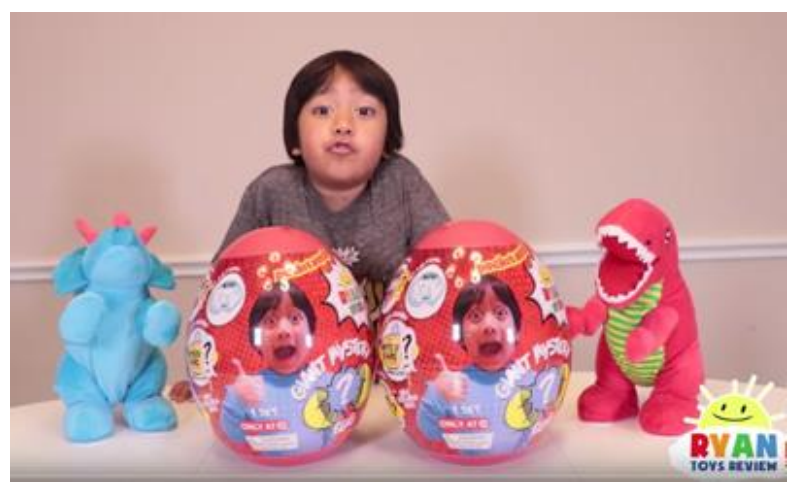

Fonte: Elaborado pelos autores.

O caso do menino Ryan é bastante emblemático pois, em 2019, ele encabeçou pelo segundo ano consecutivo a lista dos youtubers mais bem pagos do mundo. Segundo a revista Forbes $^{19}$, o pequeno faturou cerca de US\$ 26 milhões com vídeos nos quais demonstra e analisa novos lançamentos da indústria de brinquedos. Não é à toa que os vídeos unboxing se tornaram muitas vezes tão rentáveis, pois possibilitam ao mercado um canal de comunicação direta com um público difícil de acessar diante das restrições vigentes em outros canais de mídia. Trata-se de uma saída valiosa que ganha ainda mais relevância à medida que as interações on-line deixam rastros digitais que propiciam, frequentemente, a elaboração de métricas utilizadas pelas empresas para segmentar detalhadamente seus públicos de acordo com perfis ou nichos de consumo.

Fernanda Bruno (2013) chama a atenção para o fato de que os fluxos de informação que circulam no ecossistema digital se tornam foco privilegiado de monitoramento por diferentes setores, inclusive pelo mercado publicitário. Desse modo, interações desempenhadas cotidianamente nesse ambiente estariam sujeitas à coleta, ao processamento e à classificação. Em posse de uma variedade de informações com base

\footnotetext{
17 Canal Ryan's World (anteriormente intitulado Ryan ToysReview). Disponível em: <http://bit.ly/2T0r8Aj>. Acesso em: 23 jan. 2020.

${ }^{18}$ Disponível em: <http://bit.ly/2vMqq1X>. Acesso em: 23 jan. 2020.

${ }^{19}$ Disponível em: <http://bit.ly/2ubYS5w>. Acesso em: 23 jan. 2020.
} 


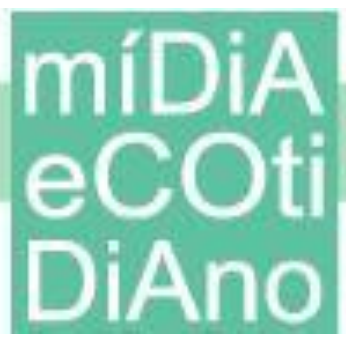

nos rastros digitais dos internautas, muitas empresas empregam esforços no intuito de otimizar a comunicação entre as marcas e seu público, de modo que pareça relevante e personalizada.

Além de fazerem uso de ferramentas que segmentam e geram padrões sobre os gostos e preferências dos consumidores, grande parte das empresas também está atenta às produções culturais dos indivíduos. Nesse quesito, inclui-se também a busca por estratégias capazes de atrair a atenção - e o coração - do público infantil. A nosso ver, os vídeos unboxing protagonizados por youtubers mirins são um exemplo de formato capaz de exercer tal função, visto que detêm a capacidade de demostrar os produtos e seus modos de uso, bem como ressaltar os estilos de vida condizentes com eles. Como argumentamos, trata-se de um formato no qual publicidade e diversão se entrelaçam, ao interpelar o público infantil, e que se configura como estratégico diante das limitações que cerceiam a publicidade dirigida à criança no Brasil.

Em meio a um cenário midiático no qual as youtubers mirins possuem grande capacidade de reunir um enorme contingente de espectadores, tomá-las como garotaspropaganda para a indústria de brinquedos se revela uma medida eficiente para aumentar o valor de seus canais e colocá-los entre os preferidos no já disputado mercado das youtubers mirins no Brasil (ANDRADE, 2019). Com vídeos divertidos e descontraídos publicados quase diariamente, essas pequenas personalidades não estariam apenas reunindo uma importante quantidade de seguidores, mas também constituindo um contingente crescente de fãs.

Para Castro (2012, p. 136), o consumidor-fã é "um tipo de agente social ao qual interessa o envolvimento mais pessoal e direto com o intangível da marca em questão". Trata-se daquele indivíduo que além de consumir os produtos, também compartilha conteúdo, participa de discussões on-line e rege sua vida pautado pelo estilo de vida proposto por sua marca predileta. Com a grande necessidade de direcionar esforços para a sedução do consumidor, de certo modo já saturado de mensagens publicitárias, o fator de identificação passa a ser perseguido pelas empresas no intuito de "transformar clientes em fãs, o consumidor em um colaborador e principal divulgador da marca" (CASTRO, 2012, p. 136). 
Essa capacidade de identificação também se revela nas produções das youtubers mirins. A todo momento busca-se gerar o reconhecimento entre o produtor (youtuber) e o consumidor (o espectador). De maneira calculada para parecer divertida e informal, as youtubers procuram se portar como uma criança comum, como qualquer outra da sua idade. Fazem isso valendo-se de um artifício reiteradamente presente nas produções: o erro. Ao invés de ser editado e deixado de fora da versão final, o erro ganha um papel de destaque objetivando conferir autenticidade ao conteúdo veiculado como uma produção infantil, despretensiosa e caseira.

Ao discorrerem sobre os motivos que levam youtubers a abarcarem gigantescos grupos de seguidores, Clotilde Peres e Eneus Trindade (2017, p. 15) argumentam que o componente de amadorismo e informalidade presente nas produções dessas figuras "sugere que estes indivíduos são semelhantes ao seu público. Esta aura amadora traz espontaneidade, descontração, empatia que possibilita o vínculo identitário com o público - o youtuber é como eu". Estabelecem, assim, um ambiente no qual o espectador passa a se constituir como seguidor e divulgador do canal: aquilo que Castro (2012) classificou como o consumidor-fã.

À medida que as crianças estão consumindo e produzindo conteúdo nessas plataformas on-line, diversas empresas infantis têm como objetivo ofertar uma gama expressiva de bens de consumo enquanto celebridades mirins entretêm e divertem outras crianças. Se bem executado, tal investimento da publicidade atual nas novas brincadeiras on-line favorece "que o consumidor esteja o maior tempo em interação positiva com as marcas" em um cenário em que "quanto mais tempo uma marca estiver na vida de uma pessoa, melhor" (CARRASCOZA, 2014, p. 60).

Conforme argumenta Tomaz (2018), com propriedade, mesmo o YouTube não sendo a princípio um espaço para crianças - como aquele que é pensado para elas -, é possível compreender que a plataforma se constitui como um espaço das crianças, uma vez que é crescentemente apropriado por elas. Essa apropriação por parte das crianças e sua exploração nas tramas da publicidade atual tem motivado preocupação e pautado diversas discussões sociais.

No começo de 2019, o Ministério Público de São Paulo entrou com uma ação civil pública contra o Google, empresa proprietária do YouTube, em que defende a 


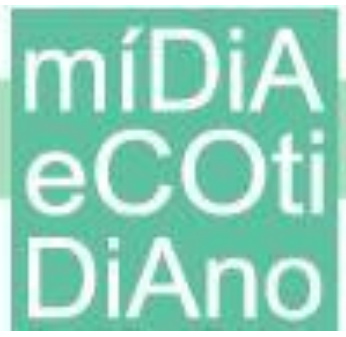

retirada do ar de uma série de vídeos de youtubers mirins que estariam fazendo propaganda velada de produtos voltados para o público infantil (BERGAMO, 2019). Nos Estados Unidos, o YouTube foi condenado a pagar uma multa recorde de cerca de US\$ 170 milhões por coletar informações pessoais de crianças e utilizá-las para lucrar com anúncios direcionados a elas. Os reguladores argumentaram que a empresa teria coletado esses dados ilegalmente, incluindo códigos de identificação usados para rastrear a navegação na web ao longo do tempo (SINGER; CONGER, 2019). Após a condenação, o YouTube anunciou, em comunicado oficial ${ }^{20}$, algumas mudanças na plataforma no intuito de oferecer maior proteção para as crianças que navegam pelo site.

No entanto, mesmo reconhecendo que as mudanças apresentadas pelo YouTube no que diz respeito à coleta e ao tratamento de dados dos consumidores de conteúdos infantis são importantes - e, sem dúvida, representam um passo fundamental para a proteção das crianças - ainda é preciso ponderar que tais mudanças não impedem a veiculação de publicidade de modo velado, por meio de formatos, inclusive o unboxing, cujo apelo comercial não é evidente e claro.

Portanto, diante dos argumentos apresentados ao longo do artigo, defendemos que o unboxing representa um formato midiático oportuno e valioso para a publicidade contemporânea, sobretudo quando destinada à criança, pois tem a capacidade de promover bens de consumo no cotidiano das brincadeiras infantis em rede. Configura-se como um formato eficaz e, ao mesmo tempo, inquietante, cuja potência se torna ainda maior à medida que marcas e brinquedos são endossados por celebridades como as youtubers mirins, driblando as regras vigentes para a comunicação publicitária voltada para crianças.

\section{Considerações finais}

Frente às regulamentações que vigoram no Brasil, diferentes empresas de produtos infantis vislumbram na atuação das pequenas youtubers um caminho fértil para demonstrar produtos e promover modos de ser e estilos de vida condizentes com o

\footnotetext{
${ }^{20}$ Disponível em: <https://youtube.googleblog.com/2019/09/an-update-on-kids.html>. Acesso em: 23 jan. 2020.
} 


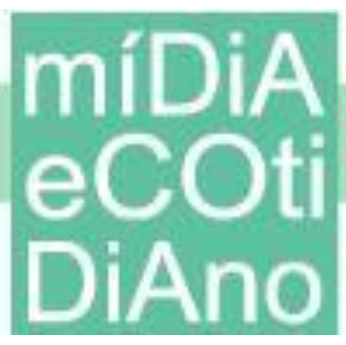

universo simbólico nos quais estão inseridos. Em tempos de dispersão da atenção e saturação da mensagem publicitária convencional, não bastaria às empresas destacar apenas os features de seus produtos. Tornou-se indispensável envolver o consumidor em um ambiente carregado de emoção e diversão. Nesse sentido, a junção das lógicas do entretenimento aos modos de fazer publicidade parece transformar a mensagem comercial em algo relevante e descontraído, atraindo a tão fragmentada atenção do consumidor em tempos de profusão de canais, formatos e telas.

Desse modo, concluímos que a prática publicitária dirigida ao público infantil no Brasil teria encontrado nos conteúdos de entretenimento, especificamente nos vídeos unboxing, uma oportuna brecha para interpelar a criança conectada às redes sociais online. Tais ações publicitárias transfiguradas de diversão têm a capacidade de driblar as regulamentações vigentes e promover não apenas bens de consumo, mas também certos estilos de vida e modos de ser criança em uma contemporaneidade crescentemente conectada. Uma prática que ganha ainda mais potência à medida que os produtos são apresentados e endossados por crianças altamente conhecidas na rede: as youtubers mirins.

Como é sabido, tornou-se frequente para as youtubers receberem aportes financeiros de diferentes empresas para demonstrarem bens de consumo em seus canais. Porém, a princípio, nos parece que os rendimentos de tais canais serão diretamente impactados devido às mudanças anunciadas pela plataforma do YouTube após o acordo firmado com a Comissão Federal de Comércio (FTC) nos Estados Unidos. Não se sabe ainda se, de fato, algo irá mudar, mas algumas inquietações surgem e podem guiar novos estudos sobre o tema. Saber qual o impacto que as mudanças apresentadas pelo YouTube terão nos rendimentos dos canais, bem como o modo com que os vídeos que fazem publicidade velada, ou seja, que mesclam publicidade e entretenimento, serão percebidos nesse novo contexto da plataforma são algumas questões a serem respondidas.

Por enquanto, ainda não sabemos se ações como essas irão ou não trazer, de fato, mudanças no modo como a atividade publicitária tem abordado o público infantil que se manifesta, interage e se diverte nas plataformas digitais. Encerramos este artigo com a clareza de que, na atual conjuntura midiática, esse público está inserido em um cenário no qual comunicação, consumo e diversão se articulam de modos nem sempre explícitos 
ou, talvez, nem mesmo lícitos, visando atrair e cativar a atenção tão fugaz da criança conectada.

\section{Referências}

ANDRADE, Marcelo. Comunicação, consumo e diversão nos vídeos unboxing: a publicidade e a criança conectada. Dissertação (Mestrado em Comunicação e Práticas de Consumo). Escola Superior de Propaganda e Marketing (ESPM), São Paulo-SP, 2019.

BERGAMO, Monica. Ministério Público pede que o Google retire do ar vídeos de youtubers mirins. Folha de S. Paulo, Ilustrada, p. C2, 2 jan. 2019.

BOYD, Danah; ELLISON, Nicole. Social network sites: definition, history, and scholarship. Journal of Computer-Mediated Communication, v. 1, n. 13, p. 210-230, 2007.

BRUNO, Fernanda. Máquinas de ver, modos de ser: vigilância, tecnologia e subjetividade. Porto Alegre: Sulina, 2013.

CARRASCOZA, João Anzanello. Estratégias criativas da publicidade: consumo e narrativa publicitária. São Paulo: Estação das Letras e Cores, 2014

CASTRO, Gisela. Lindas para sempre, jovens de coração: imagens do envelhecimento na publicidade natalina. In: CASTRO, G. Os velhos na propaganda: atualizando o debate (Org.). São Paulo: Pimenta Cultural, 2018, p. 73-101.

CASTRO, Gisela. Entretenimento, sociabilidade e consumo nas redes sociais: cativando o consumidor fã. Fronteiras: estudos midiáticos, v. 14, n. 2, p. 133-140, mai. /ago., 2012.

CGI.BR. Pesquisa sobre o uso das tecnologias da informação e comunicação nos domicílios brasileiros: TIC Domicílios 2018. São Paulo: Comitê Gestor da Internet no Brasil, 2019.

CGI.BR. Pesquisa sobre o uso das tecnologias da informação e comunicação nos domicílios brasileiros: TIC Domicílios 2017. São Paulo: Comitê Gestor da Internet no Brasil, 2018.

CGI.BR. Pesquisa sobre o uso das tecnologias da informação e comunicação nos domicílios brasileiros: TIC Domicílios 2016. São Paulo: Comitê Gestor da Internet no Brasil, 2017.

CORRÊA, Luciana. Geração YouTube: um mapeamento sobre o consumo e a produção de vídeos por crianças. ESPM: São Paulo, 2016.

CORREAA, Luciana. Geração YouTube: um mapeamento sobre o consumo e a produção de vídeos por crianças. ESPM: São Paulo, 2015.

COVALESKI, Rogério. Publicidade híbrida. Curitiba: Maxi Editora, 2010.

CRAVEIRO, Pâmela; BRAGAGLIA, Ana Paula. Regulação da publicidade infantil no Brasil: a publicidade após a resolução 163 do Conanda. In: ALCÂNTARA, A.; GUEDES B. (Orgs.).

Comunicação e infância: processos em perspectiva. São Paulo: Pimenta Cultural, 2017, p. 62 94. 
FEATHERSTONE, Mike. Cultura de consumo e pós-modernismo. São Paulo: Studio Nobel, 1995.

FELDMAN, Dana. LOL Surprise is the top doll with over $2.5 \mathrm{~m}$ sold in five months. Forbes, $\mathrm{n}$. 19, abr. 2017. Disponível em: <https://www.forbes.com/sites/danafeldman/2017/04/19/1-o-1surprise-is-the-top-doll-with-over-2-5m-sold-in-five-months/>. Acesso em: 31 jan. 2020.

FONTENELLE, Isleide. Cultura do consumo: fundamentos e formas contemporâneas. Rio de Janeiro: FGV, 2017.

FREIRE FILHO, João. Mídia, consumo cultural e estilo de vida na pós-modernidade. ECOPÓS, v. 6, n.1, p. 72-97, jan. /jul., 2003.

KARAGEORGIADIS, Ekaterine. O sistema brasileiro. In: HENRIQUES, I.; VIVARTA, V. Autorregulação da publicidade infantil no Brasil e no mundo. São Paulo: Verbatim / Instituto Alana, 2017.

LEÃO, Danuta; PRESSLER, Neusa. Youtuber mirim e o consumo infantil. $40^{\circ}$ Congresso Brasileiro de Ciências da Comunicação, Anais..., Curitiba, 2017. Disponível em: <http://bit.ly/2HFng2K>. Acesso em: 23 jan. 2020.

OROFINO, Maria Isabel. O ponto de vista da criança no debate sobre comunicação e consumo. Revista Latinoamericana de Ciencias Sociales, Niñez y Juventud, v. 13, n. 1, p. 369-381, 2015.

PERES, Clotilde; TRINDADE, Eneus. Consumo midiático: youtubers e suas milhões de visualizações. Como explicar? $26^{\circ}$ Congresso Nacional dos Programas de Pós-Graduação em Comunicação, Anais..., São Paulo, 2017. Disponível em: 〈http://bit.ly/37D273z>. Acesso em: 23 jan. 2020.

SILVERSTONE, Roger. Por que estudar a mídia? São Paulo: Loyola, 2002

SINGER Natasha.; CONGER, Kate. Google is fined \$170 million for violating children's privacy on YouTube. The New York Times, 4 set. 2019. Disponível em: <https://nyti.ms/2T1tSOd>. Acesso em: 31 jan. 2020.

SLATER, Don. Cultura do consumo \& modernidade. São Paulo: Nobel, 2002.

TOMAZ, Renata. Uma janela para as crianças: a construção social do YouTube como lugar de produção de subjetividades infantis. $41^{\circ}$ Congresso Brasileiro de Ciências da Comunicação, Anais..., Joinville, 2018. Disponível em: <http://bit.ly/3bKVsI1>. Acesso em: 23 jan. 2020.

TOMAZ, Renata. O que você vai ser antes de crescer? - youtubers, infância e celebridade. Tese (Doutorado em Comunicação e Cultura). Universidade Federal do Rio de Janeiro, Rio de Janeiro-RJ, 2017. 